\title{
Face masks, sinonasal quality of life and COVID-19 pandemic
}

\author{
Rujittika Mungmunpuntipantip $^{1}\left[\right.$ (1) Viroj Wiwanitkit ${ }^{2}$
}

Received: 29 October 2021 / Accepted: 3 November 2021 / Published online: 26 November 2021

(c) The Author(s), under exclusive licence to Springer-Verlag GmbH Germany, part of Springer Nature 2021

\section{Dear Editor,}

We would like to share ideas on "How face masks influence the sinonasal quality of life during the COVID-19 pandemic [1]." Et al. concluded that "The majority of our survey's responders, predominantly female .... produce more "airway-minded" personal protection equipment [1]". The reply by responders in the present study might reflect feeling but it might or might not affect a real anatomical-physiological problem resulting from facemask wearing. Indeed, there are many types of facemasks and the physical impact on the face, especially for sinonasal are, might be different. A long-time use of a facemask might cause pressure sores on the ears and nose bridge if the mask is not fit with the face shape of the facemask wearer [2]. In a recent report from Africa, ones who did not wear facemask usually mentioned for discomfort feeling [3]. A quality control of material and design of facemask should not be overlooked. Similar to other piece of dressings, various size and design of facemask to promote comfort for wearer might be an important clue to increase facemask wearing rate in the present COVID-19 pandemic situation.

\section{Declarations}

Conflict of interest The authors declare that they have no conflict of interest.

\section{References}

1. Fever AP, Amir O, Roziner I, Segal RM, Alon EE, Yakirevitch A (2021) How face masks influence the sinonasal quality of life during the COVID-19 pandemic. Eur Arch Otorhinolaryngol. https:// doi.org/10.1007/s00405-021-06752-2 (Epub ahead of print)

2. Luo P, Liu D, Li J (2020) Topical recombinant human acidic fibroblast growth factor: an effective therapeutic agent for facemask wearing-induced pressure sores. Dermatol Ther 33(4):e13745

3. Natnael T, Alemnew Y, Berihun G, Abebe M, Andualem A, Ademe S, Tegegne B, Adane M (2021) Facemask wearing to prevent COVID-19 transmission and associated factors among taxi drivers in Dessie City and Kombolcha Town, Ethiopia. PLoS ONE 16(3):e0247954

Publisher's Note Springer Nature remains neutral with regard to jurisdictional claims in published maps and institutional affiliations.

This comment refers to the article available online at https://doi. org/10.1007/s00405-021-06752-2.

Rujittika Mungmunpuntipantip

rujittika@gmail.com

Bangkok, Thailand

2 Dr DY Patil University, Pune, India 